\title{
Short Circuit and Stability Analysis of a Multi- Machine System with Wind Turbine Using the ETAP Program
}

\author{
Sara Ismail Abd-Al Huseen ${ }^{1}$, Rushed Almansory ${ }^{2}$ \\ \{s.ismail@fgs.stu.edu.iq ${ }^{1}$, r.s.almansory@stu.edu.iq $\left.{ }^{2}\right\}$ \\ Southern Technical University, Technical Engineering College, Iraq, Basrah ${ }^{1,2}$
}

\begin{abstract}
This study focuses on the effects of a multi-machine 12 bus system-connected wind power plant (WPP) on the impact of variations in turbulences happening on multiple buses during service. The DFIG-based wind turbine was considered in this paper to assess the presentation features of DFIG For load current study, Short circuit study then transient stability. ETAP program analyzed the imitation effects the outcomes of the imitation display that a system disturbance that happens in a wind turbine-connected multimachine scheme does not lead to a reduction in the bus close the fault thendecreases the constancy.
\end{abstract}

Keywords: WPP, Multi-Machine, DFIG, ETAP.

\section{Introduction}

Turbines (WT) with initiation engines are commonly used to provide a native load and power directly to the grid. Transient phenomena can occur During the start and braking time of the WT [1]. Stability is contingent on both the initial state of activity and the intensity of the disruption. Vishal Vaman Mehtre, Shripad Ganapati Desai, Prof. Dr. D.S. Bankar [2] The functional features of DFIG were evaluated using power flow analysis, short circuit analysis, harmonic analysis, and ideal load flow evaluation in this paper. Aman J, Mukesh K, Abhinav K, Rahul K [3] They discuss the analysis of the stability and transients of a multi-machine system using the ETAP program and explain the effect of the stability of the power system (PSS). Archana R, Subramaniya Siva A [4] It presents an integrated system for wind energy in a transmission system (IEEE) 30 bus with photovoltaic energy. This idea came as a result of bad weather conditions, which have an impact on the system, where the voltage, stability, and level of harmonic distortion are controlled. B A Ashad, A Siswanto, I C Gunadin, and Yusran [5] This study provides a new step for modeling disturbances in multi-machine systems connected to wind turbines and the effects of wind power in a vector system 9 bus and argues that the error can have a small moment of inertia sufficient to make it unstable. When it comes to checking temperature boundaries or stable state frequency regulation, wind power is close to any other form of electricity generation. However, during and after disruptions, the activity of wind turbines is diverse from that of traditional generators [6]. Readings and studies to evaluate the behavior of a wind turbine power scheme through transient disruptions that can lead to loss of generation stability in reference [7]. On the other hand, Additional difficulties in 
voltage/frequency regulation, as well as reactive capacity reparations, can arise as a result of the introduction of wind energy, power value (e.g. harmonic distortion and flicker), and delivery system safety. Wind energy can be shared with enough compensators to improve the power circulation device's process $[1,8]$. Wind power is usually produced by wind generators, which can operate at either a fixed or variable speed. The latter is distinguishable as it has more power for a given speed, optimal mechanical stability, lower mechanical forces, and lower excessive noise [9]. There are usually four types of generators in the latest developments in wind power conversion. Kind 1 is a fixed speed induction generator, kind 2 is a variable rotor resistance induction generator, kind 3 is a partial-scale power converter variable speed wind turbine design, and kind 4 is a full-scale power converter variable speed concept. In this article, the generator form 3 is used [10]. ETAP is the most detailed and thorough power system analysis program available, analysis, tracking, application, regulator, efficiency, and optimization. Real-time simulation, dynamic load shedding, optimal load flow, and cost optimization are among ETAP's unique features [11]. The load flow and transient stability in a device consisting of a double-fed induction generator (DFIG) wind turbine and a synchronous generator were investigated in this study using ETAP software with a limit of 12 buses. In the second section of the research, how DFIG works is discussed, while in the third section the system model is explained in detail, and in the fourth section, the load flow and short circuit of the system are studied with some illustrations and results represented by the tables and discussed, and in the fifth, the transient stability test is conducted with the proposed model in the presence of And the absence of a wind turbine, and in the sixth, some special concepts of modeling and stability of the system are presented with the mention of mathematical equations, and finally, in the seventh, the research work is concluded with mentioning the advantages and disadvantages.

\section{Induction generator with two feeds (DFIG)}

The main energy source will no longer be controlled, the use of DFIG has Become a viable plus effective option for power production. Its feasibility and efficiency are attributable to the Capacity of the Converters to control the excitation of the system rotor field, as shown in Fig 1 [12]. A wound rotor generator and a PWM transformer operating on an AC/DC/AC IGBT are included in the DFIG. As compared to traditional wind generators, it has a higher dynamic performance throughout grid outages, the idea of a variable-speed wind turbine (VSWT) fitted with a doubly fed induction generator (DFIG) is gaining traction. The induction generator system (DFIG) is a more straightforward and cost-effective alternative to the synchronous machine. In the DFIG converter, a dc-link capacitor connects a rotor-side converter (RSC) and a grid-side converter (GSC). This converter's necessary rating is usually $25-30 \%$ of whole scheme capacity, which lowers converter costs, decreases harmonics infusion into the linked grid, and improves the wind turbine system's overall performance [13].DFIG's key benefit lies in its capacity to work at very low wind speeds and high wind speeds. The reactive influence is fed into the grid to prevent Power absorption from the grid and thus voltage disruption is minimized, thus over-ruling the need for reactive power compensation [14]. With a little wind speed, DFIG is very powerful. DFIG is during fault conditions Capable of handling higher current values without disrupting the device [2]. A changeable wind turbine, particularly in light wind conditions, makes better use of the available wind resources than a fixed-speed wind turbine [4]. 


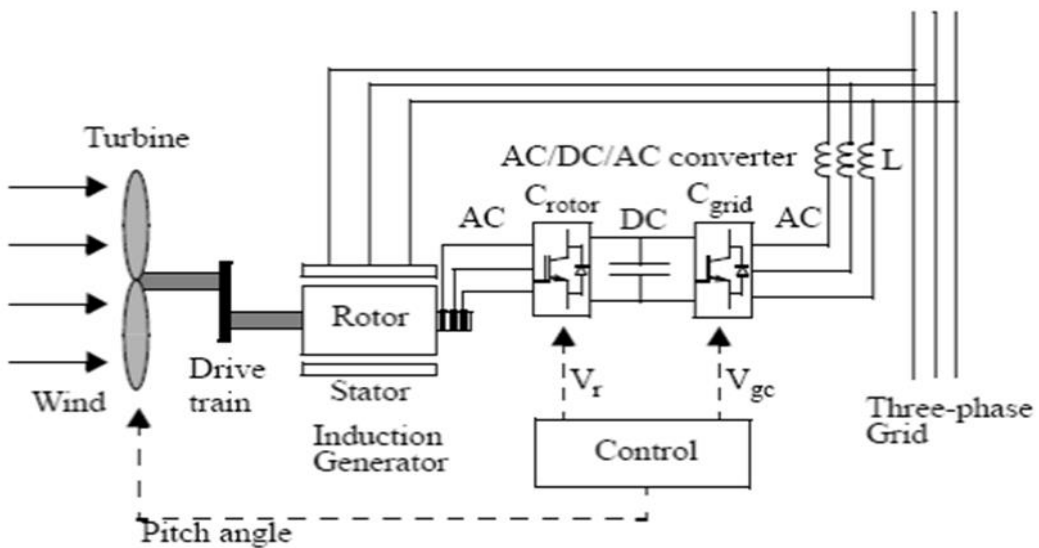

Fig. 1. Double fed induction generator

\section{Model of Power System}

Fig. 2 shows a single-line schematic of the model used to examine the performance of multimachine interconnected wind turbines during unexpected short circuit events during simulation. This system involves a converter substation, $13.8 \mathrm{kV}$, and a three-sub feeder delivery system that is linked to a wide network via a $69 \mathrm{kV}$ longitudinal cable. To retain voltage and frequency power, the $13.8 \mathrm{kV}$ delivery power plant is fitted with a three-phase fixed shunt dc link. A transformer connects the grid to a $69 \mathrm{kV}, 1000 \mathrm{MVA}$ fault current storage bus. The scheme consists of three radial lines with four feeders L1 (1.082MVA ), L2 (1MVA),L3 (0.5 MVA),L4 (0.5 MVA) .between bus 4 and 5, 11 and 12,considered two operated 13.8/0.48 KV, 1.5 and 1 MVA step-up transformers. And between bus 6 and bus 7, 9 and 10, considered two operated 13.8/2.4KV step-up transformer. Between bus 3 and 2 considered operated 69/13.8KV main step-up transformer. With one wind turbine generator $(2.1 \mathrm{MW})$ at bus 4 and an asynchronous generator (4.25 MW) at bus 8 . 


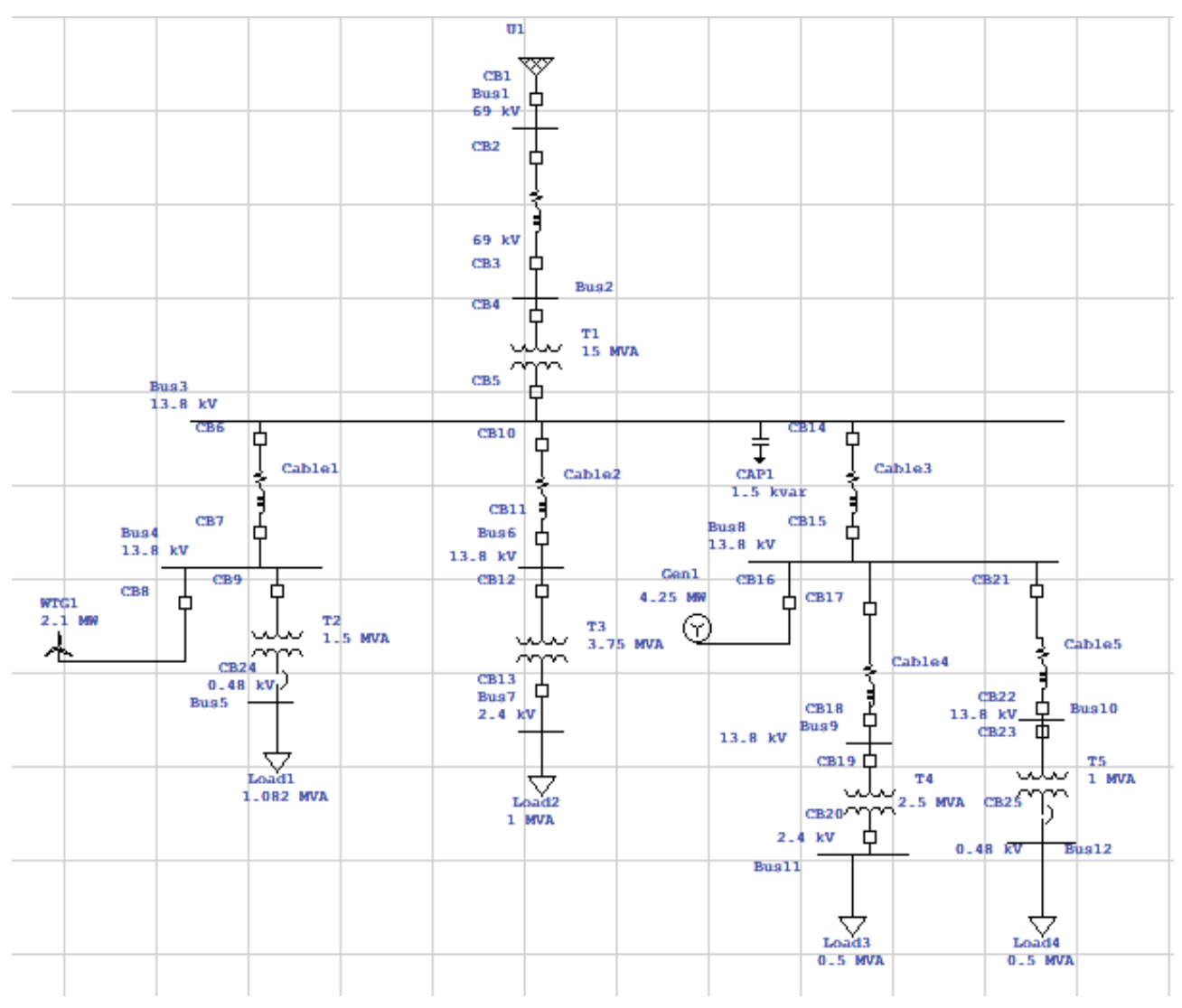

Fig. 2: 12-bus Multi-machine with wind turbine generator [12].

\section{The system's load flow and short circuit study}

\subsection{Load Flow Study}

Analysis of Load Flow has been tracked under the ETAP program. The Load Flow Analysis is capable of Separately Specifying and changing the device parameters for each event. ETAP has several options to identify the display options based on the load flow analysis needs and specifications of the user. In the 12 bus method, Power flow is measured using the adaptive Newton RAPHSON load flow algorithm. For analysis, Wind velocity is taken as the nominal. $963 \mathrm{KW}$ and $82 \mathrm{KVAR}$ are both real and reactive capacity close to the network as shown in Fig 3. 


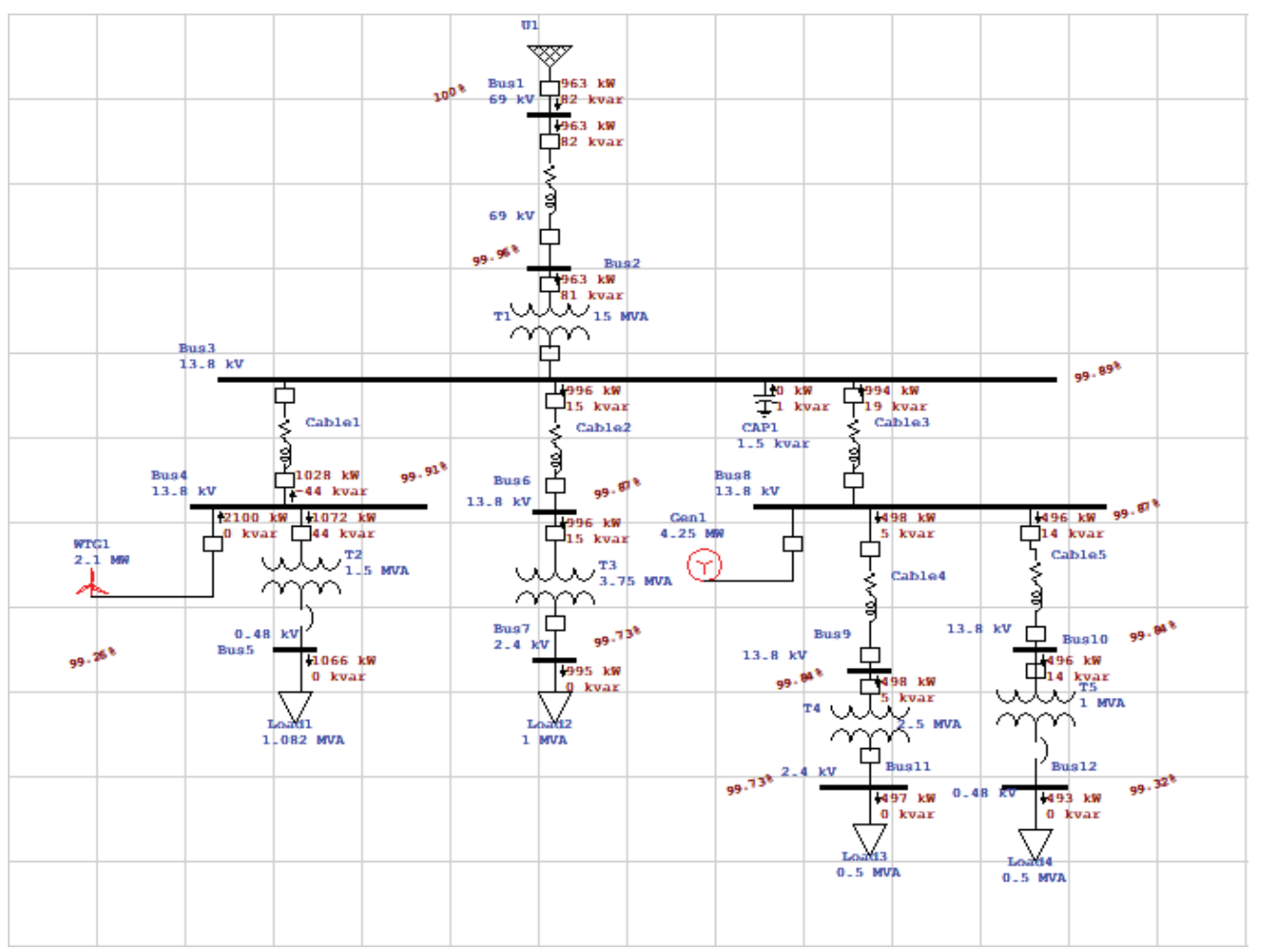

Fig. 3: Load flow (analysis result of the system).

Results of the load flow study of the 12-bus system has been observed that the bus voltages are increased by $100 \%, 99.959 \%, 99.890 \%, 99.914 \%, 99.866 \%, 99.728 \%$, $99.867 \%, 99.843 \%, 99.843 \%, 99.735 \%$ in bus no $1,2,3,4,6,7,8,9,10,11$ respectively and decreased by $99.256 \%, 99.318$ in bus no 5,12 .

\subsection{Short Circuit Analysis}

For the circuit breaker study, the capacity of the ETAP program was measured. The willingness of the machine to adjust to its normal state, as well as the main protective equipment's ranking, Are the most important factors in short circuit research. The device is shown in Figs 4, 5 before joining the wind turbine introducing a 12 bus fleet, a generator for bus 8 , loads for buses 5,7 , 10 , and 12 . 


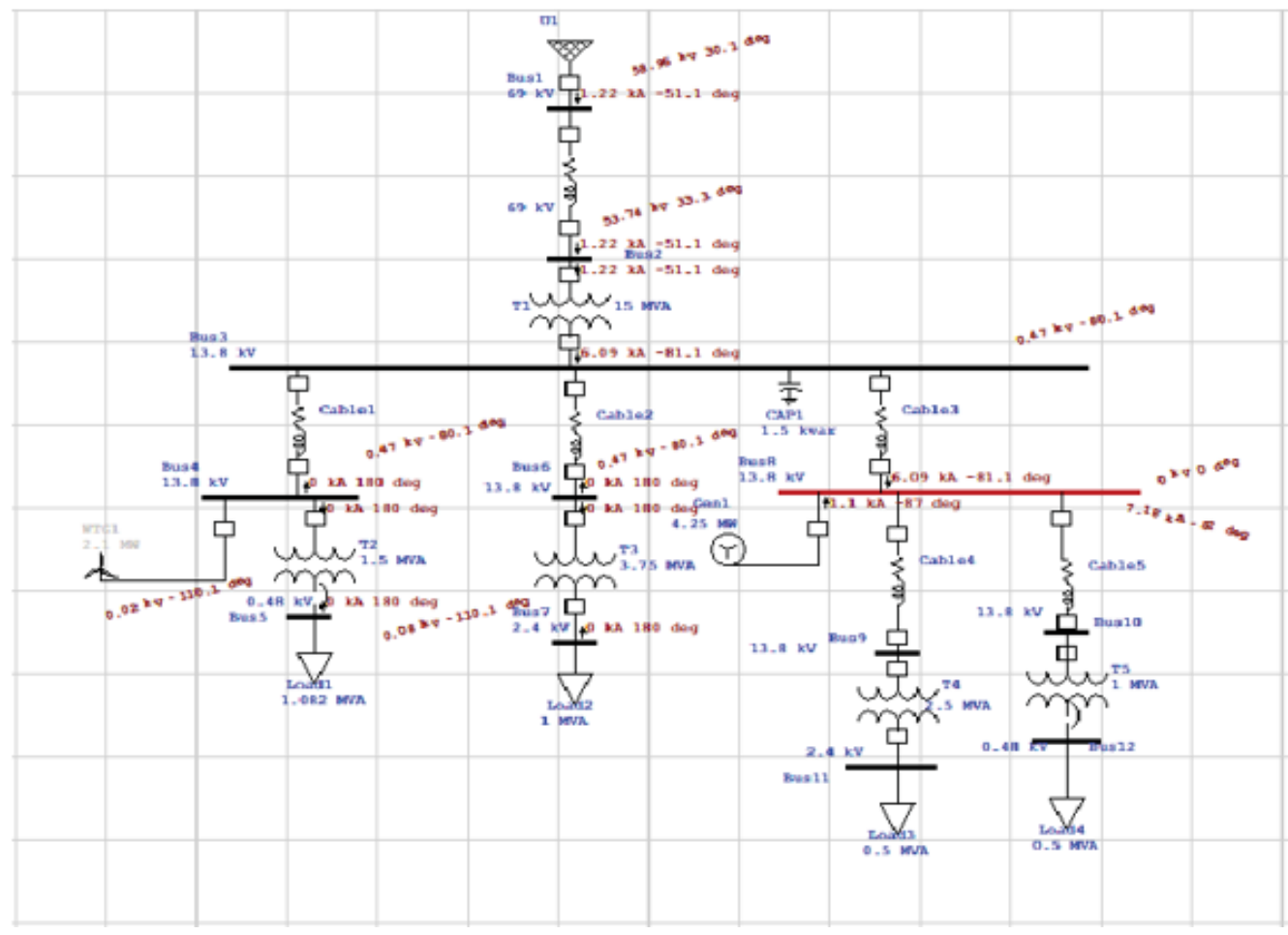

Fig .4: Error in bus bar 8 . 


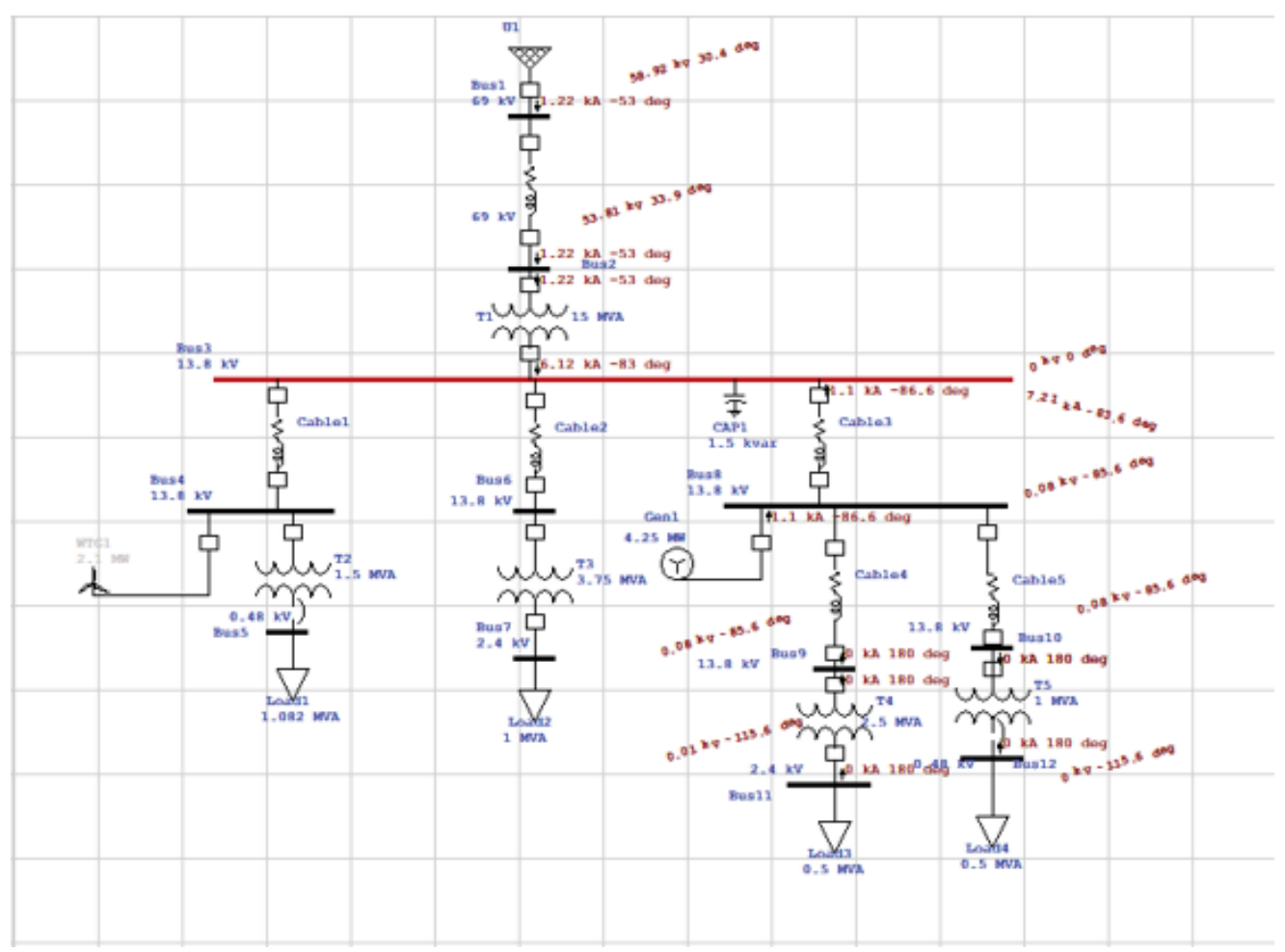

Fig. 5: Error in bus bar 3 .

Table 1 . Voltages on each bus before entering a wind turbine

\begin{tabular}{|c|c|c|c|}
\hline Buses & $\begin{array}{l}\text { Voltages } \\
\text { ofbuses }\end{array}$ & $\begin{array}{c}\text { Error at bus } \\
3\end{array}$ & $\begin{array}{c}\text { Error at bus } \\
8\end{array}$ \\
\hline 1 & $69 \mathrm{KV}$ & $58.92 \mathrm{KV}$ & $58.96 \mathrm{KV}$ \\
\hline 2 & $69 \mathrm{KV}$ & $53.81 \mathrm{KV}$ & $53.74 \mathrm{KV}$ \\
\hline 3 & $13.8 \mathrm{KV}$ & $0 \mathrm{KV}$ & $0.47 \mathrm{KV}$ \\
\hline 4 & $13.8 \mathrm{KV}$ & - & $0.47 \mathrm{KV}$ \\
\hline 5 & $0.48 \mathrm{KV}$ & - & $0.02 \mathrm{KV}$ \\
\hline 6 & $13.8 \mathrm{KV}$ & - & $0.47 \mathrm{KV}$ \\
\hline 7 & $2.4 \mathrm{KV}$ & - & $0.08 \mathrm{KV}$ \\
\hline 8 & $13.8 \mathrm{KV}$ & $0.08 \mathrm{KV}$ & $0 \mathrm{KV}$ \\
\hline 9 & $13.8 \mathrm{KV}$ & $0.08 \mathrm{KV}$ & - \\
\hline 10 & $2.4 \mathrm{KV}$ & $0.08 \mathrm{KV}$ & - \\
\hline 11 & $13.8 \mathrm{KV}$ & $0.01 \mathrm{KV}$ & - \\
\hline 12 & $0.48 \mathrm{KV}$ & $0 \mathrm{KV}$ & - \\
\hline
\end{tabular}

Case 1: Absence of wind turbine and presence of a synchronous generator

Results of short circuit analysis in the absence of wind turbines are shown in Table 1, when a breakdown occurs on Bus No. 3, we note that the voltage results are higher on Bus No. 1 and drop to zero on Bus No. 12 and Bus No. 4,5,6,7 out of the work. Otherwise, when there is a fault 
on Bus no 8, the results of the voltages are the Maximum on Bus No. 1 and the Minimum on Bus No. 5 and Bus No. 9, 10, 11, and 12 are out of the work.

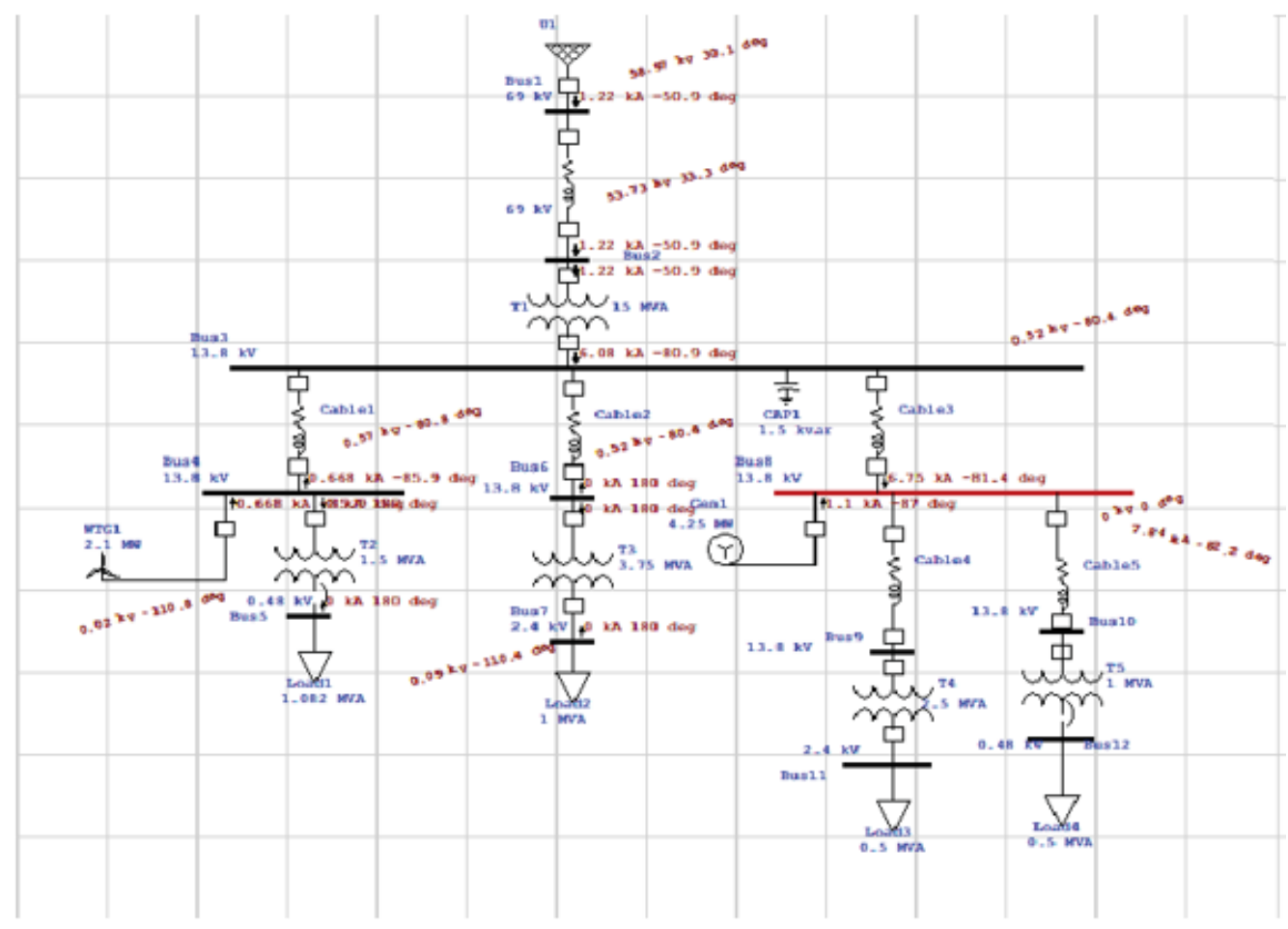

Fig .6: Error in bus bar 8 . 


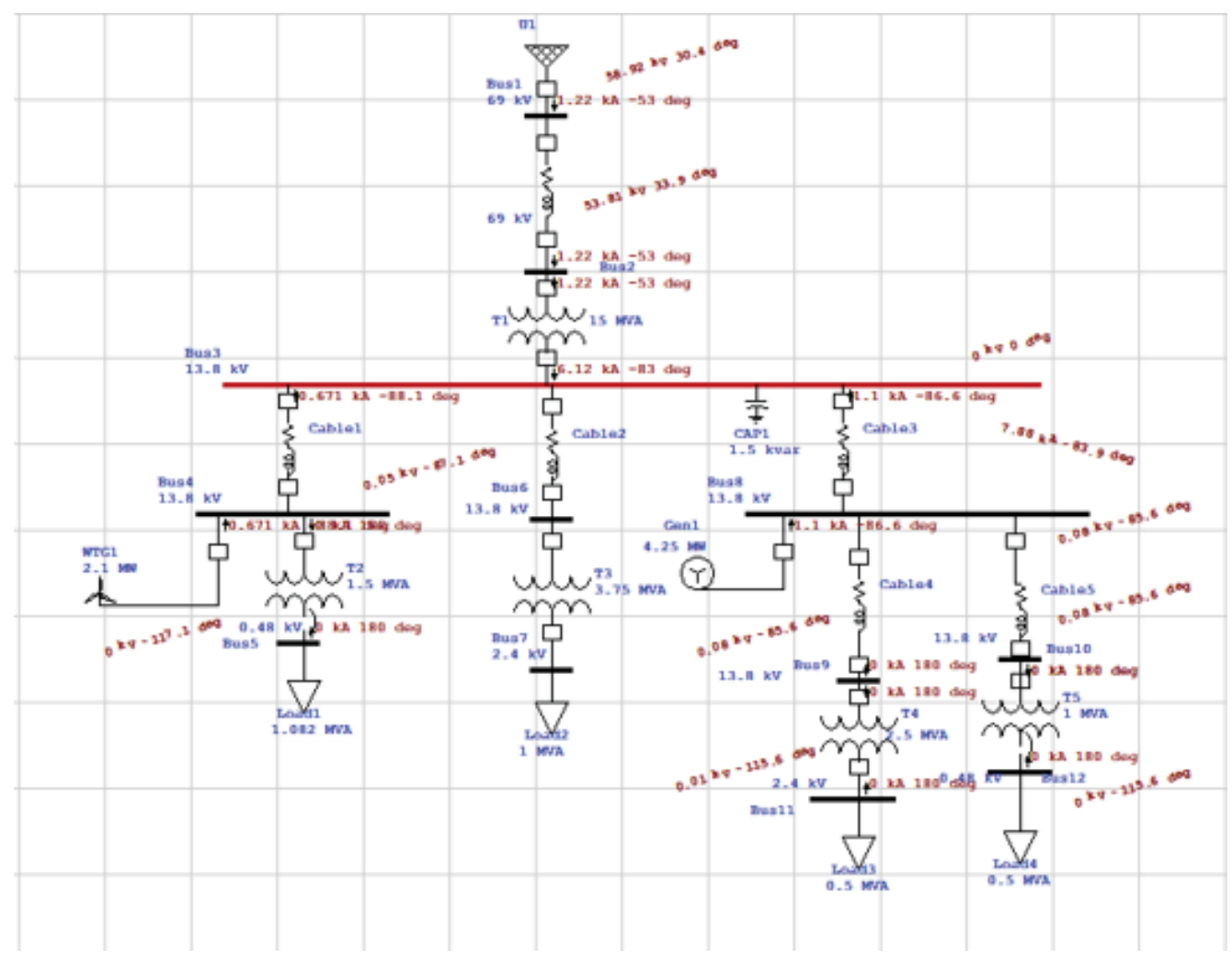

Fig. 7: Error in bus bar 3

Table 2. Voltages on each bus after entering a wind turbine

\begin{tabular}{|r|r|c|c|}
\hline buses & $\begin{array}{c}\text { Voltages } \\
\text { of buses }\end{array}$ & Error at bus 3 & Error at bus 8 \\
\hline 1 & $69 \mathrm{KV}$ & $58.92 \mathrm{KV}$ & $58.97 \mathrm{KV}$ \\
\hline 2 & $69 \mathrm{KV}$ & $53.81 \mathrm{KV}$ & $53.73 \mathrm{KV}$ \\
\hline 3 & $13.8 \mathrm{KV}$ & $\begin{array}{c}0 \mathrm{~K} \\
\mathrm{~V}\end{array}$ & $0.52 \mathrm{KV}$ \\
\hline 4 & $13.8 \mathrm{KV}$ & $0.05 \mathrm{KV}$ & $0.57 \mathrm{KV}$ \\
\hline 5 & $0.48 \mathrm{KV}$ & $0 \mathrm{KV}$ & $0.02 \mathrm{KV}$ \\
\hline 6 & $13.8 \mathrm{KV}$ & - & $0.52 \mathrm{KV}$ \\
\hline 7 & $2.4 \mathrm{KV}$ & - & $0.09 \mathrm{KV}$ \\
\hline 8 & $13.8 \mathrm{KV}$ & $0.08 \mathrm{KV}$ & $0 \mathrm{KV}$ \\
\hline 9 & $13.8 \mathrm{KV}$ & $0.08 \mathrm{KV}$ & - \\
\hline 10 & $2.4 \mathrm{KV}$ & $0.08 \mathrm{KV}$ & - \\
\hline 11 & $13.8 \mathrm{KV}$ & $0.01 \mathrm{KV}$ & - \\
\hline 12 & $0.48 \mathrm{KV}$ & $0 \mathrm{~K}$ & - \\
& & $\mathrm{V}$ & \\
\hline
\end{tabular}

Case2: wind turbine and sync generator are present 
When a fault occurs on Bus No. 3, we observe that the voltage results are higher on Bus No. 1 and decrease to zero On Bus No. 5, 12, and Bus No. 6, 7 out of the work. Otherwise, when there is a fault on Bus no 8, the introduction of a wind turbine does not affect on results.

\section{Transient Stability system under test Transient Stability Analysis event}

At time $\mathrm{t}=10 \mathrm{sec}$, the circuit breaker is triggered on bus 4 and cleared at time $\mathrm{t}=10.5 \mathrm{sec}$. In the models, the 30-sec Simulations involve electromagnetic transients, but saturation is not included. When failure occurs, there is a large difference in voltage through transient conditions, and positive sequence current Fluctuations are often very strong. On the other hand, because of the combination of DG, these variations cannot be avoided. It injects the device with full reactive power and the voltage incomes to its usual range. When an error happens, the DG device supplies reactive power. Before installing a wind turbine, the fault in Figures 8 and 9 of Bus 4 has little effect on the major grid's real and reactive power.

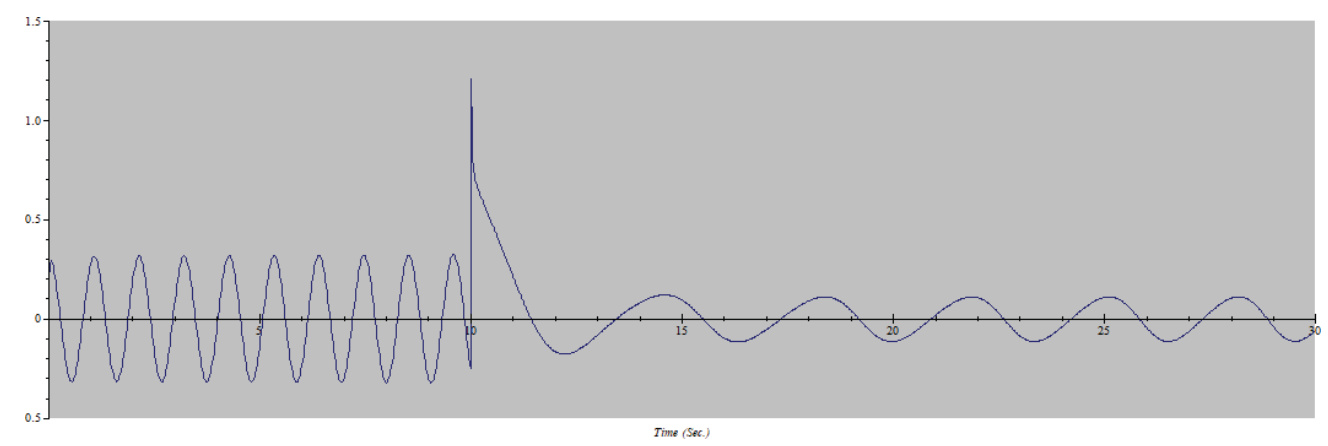

Fig. 8: bus 4. Synchronous Generator: Active power MW (Before adding a wind turbine)

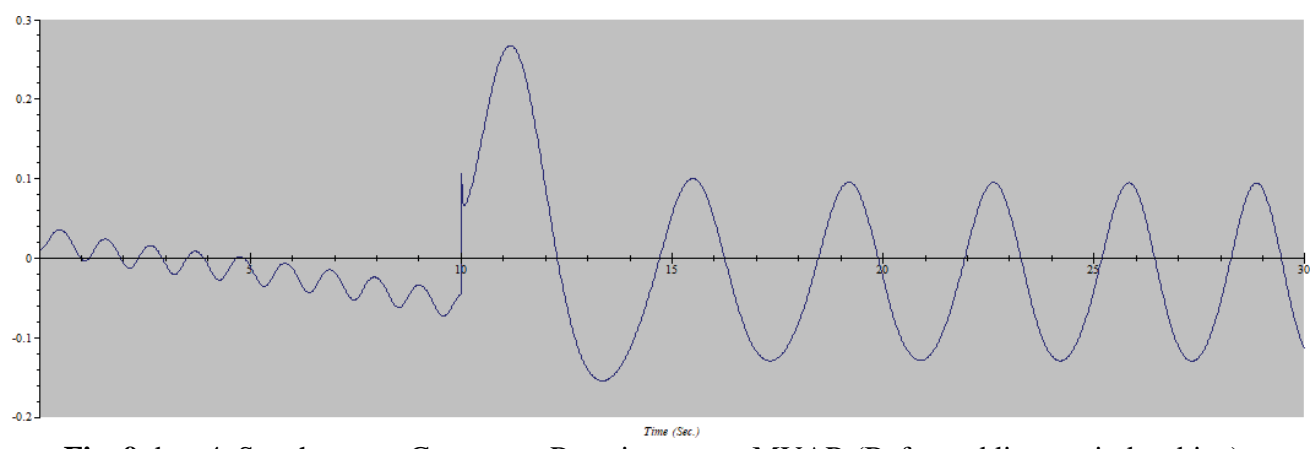

Fig. 9: bus 4. Synchronous Generator: Reactive power MVAR (Before adding a wind turbine)

Now when the synchronous wind turbine has been linked to the device, a short circuit case has been established on bus 8 for time $\mathrm{t}=10$ seconds and resolved at $\mathrm{t}=10.5$ seconds, The simulation has been run for 30 seconds, the wind turbine's power is $5 \mathrm{MW}$, and wind speed is the main factor, as shown in Figures 10 and 11. For simulation, the wind speed may vary from $8 \mathrm{~m} / \mathrm{s}$ to $12 \mathrm{~m} / \mathrm{s}$. Due to the wind turbine itself delivering compensating VARs, the patterns in reactive and actual power are slightly different. 


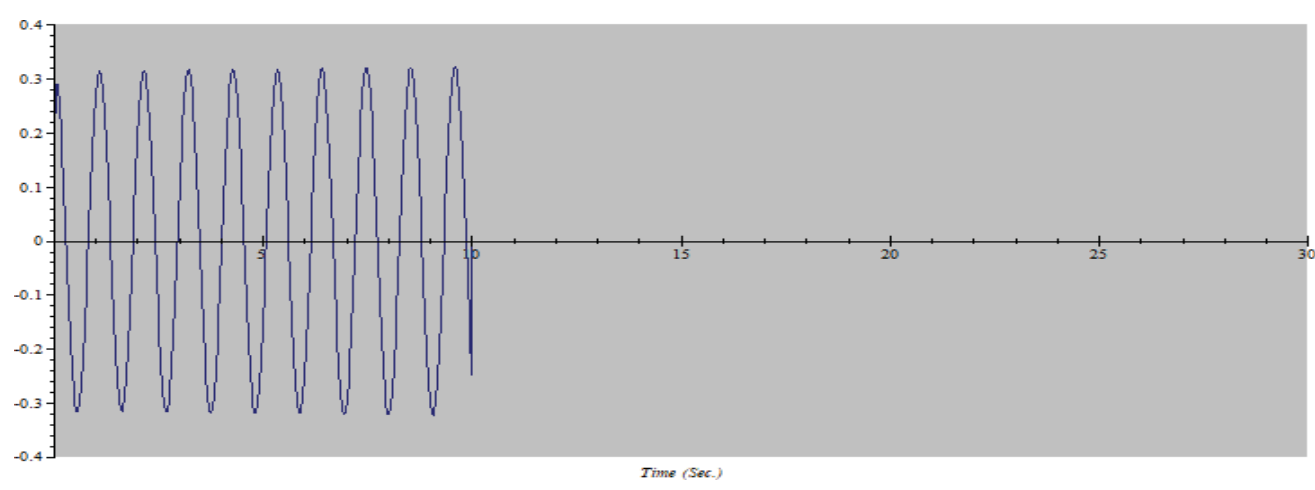

Fig .10: bus 8. Synchronous Generator: Active power MW (after adding a wind turbine)

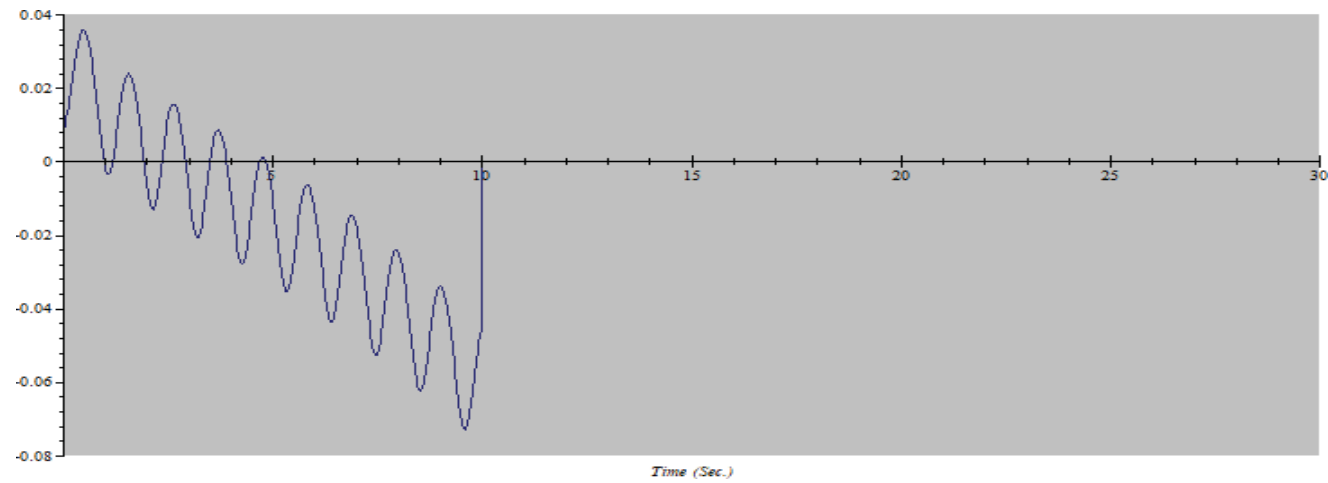

Fig .11: Bus 8. Synchronous Generator: Reactive power MVAR (after adding a wind turbine)

\section{Remarks on the Result:}

The studies of stability analysis are conducted in four situations. In table 3 , the results of transient trials, events, and observations are listed.

Table 3. The study's overview reveals

\begin{tabular}{|l|l|l|}
\hline Events & $\begin{array}{l}\text { Due to a fault, the generation } \\
\text { isdown. }\end{array}$ & Study \\
\hline Event 1 & Fault on bus 4 & $\begin{array}{l}\text { Since the synchronous can supply the load, the winding } \\
\text { mechanism has no negative impact on the project. }\end{array}$ \\
\hline Event 2 & Fault on bus 8 & $\begin{array}{l}\text { Since the wind turbines are insufficient to supply the } \\
\text { load, Generator G1 will quickly lose its balance. }\end{array}$ \\
\hline
\end{tabular}

\section{Modeling Concerns for Wind Turbine and Stability Equations}

Whenever a mechanism is disturbed, its stability refers to its ability to adjust to its stable state. As described earlier, Electricity is produced by synchronous machines which are in sync with the rest of the system. As a result, a Balancer can be described as the capacity of a power supply to restore to a stable equilibrium before losing equilibrium. Random variations in load and 
production stages cause these minor disruptions. These slight changes may cause catastrophic failure in a power system network because they force the rotor angle to high voltage [15].

Multi-machine network disruption is a safety issue that causes changes in grid integration and voltage on the power system linked to the wind turbine, which affects multi-machine systems [5]. As shown in Fig 12, the wind turbine design with DFIG is made up of the following components: wind speed model, aerodynamic model, mechanical model, DFIG model, protection model for back-to-back multilevel inverters, and transformer. The following equations define the aerodynamic model.

$\lambda=(\omega \mathrm{M} \mathrm{R}) / \mathrm{V}$

$\mathrm{PM}=(1 / 2) \rho \pi \mathrm{R} 2 \mathrm{~V} 3$

$\mathrm{TM}=\mathrm{PM} / \omega \mathrm{M}=(1 / 2 \lambda) \rho \pi \mathrm{R} 3 \mathrm{~V} 2 \mathrm{CP}$

Where $\lambda$ is the tip-to-ground speed ratio, $\omega$ is the blade angular velocity $(\mathrm{rad} / \mathrm{s}), \mathrm{R}$ is the blade radium $(\mathrm{m}), \mathrm{V}$ is the wind speed $(\mathrm{m} / \mathrm{s}), \mathrm{PM}$ is the machine-driven power from wind $(\mathrm{KW}), \rho$ is the air strength $(\mathrm{Kg} / \mathrm{m} 3), \mathrm{CP}$ is the Factor of strength. The power factor is greatest at a certain rate of the tip speed ratio. The maximum power Can be captured by a wind turbine with DFIG by achieving the optimum tip speed ratio under the valued wind Speed. Pitch regulation and DFIG control restrict the captured power to the valued energy overhead the valued wind speed, leaving the optimum power coefficient operation [16].

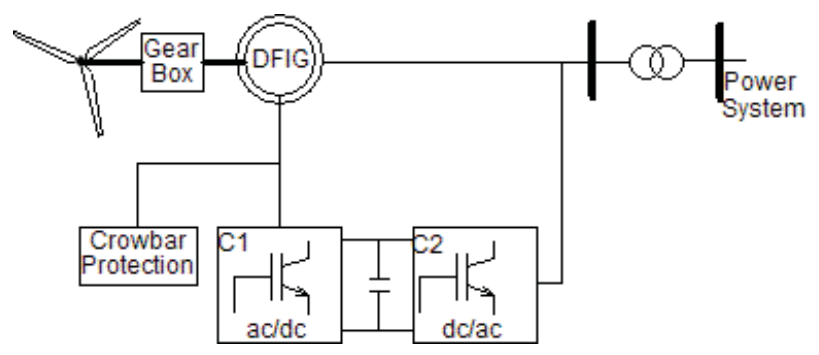

Fig. 12: Wind turbine with DFIG

When a system is exposed to significant or extreme disruptions, transient stability studies determine whether synchronism is maintained or not. A short circuit, a loss of a sudden large load, or a loss of generation is all examples of disturbances. A temporary stability testing aims to see if the load angle incomes to a stable value after the disruption have passed. To decide the constancy, nonlinear equations are solved. Transient stability is the focus of the Equal Area Criterion. It is, in reality, a very simple graphical method that is employed. It is used to determine the transient stability of a single machine or two-machine device in the presence of an infinite bus [3].

Swing Equation: The swing formula is a time-dependent expression for the gravitational attraction of the rotor with respect to the stator field.

For generator, $\mathrm{Tag}=\mathrm{T} \mathrm{s}-\mathrm{T} \mathrm{e}$

$$
\text { =Input Torque }- \text { Out put Torque }
$$


For motor, $\mathrm{Pa} \mathrm{g}=\mathrm{P} \mathrm{s}-\mathrm{P}$ e

$=$ Input Power - Out put Power

As angular displacement always varying so its measure is difficult w.r.t synchronously rotating axis

$$
\begin{aligned}
& \Theta=W s . t+d \\
& \mathrm{~d} \Theta / d \mathrm{t}=\mathrm{d} / \mathrm{d} \mathrm{t}(\mathrm{Ws} . \mathrm{t}+\mathrm{d}) \\
& \mathrm{d} 2 \mathrm{\Theta} / \mathrm{d} \mathrm{t} 2=\mathrm{d} 2 \mathrm{~d} / \mathrm{d} \mathrm{t} 2=\alpha \\
& \mathrm{M} 2 \mathrm{~d} / \mathrm{dt} 2=\mathrm{P} \mathrm{s}-\mathrm{P} \text { e }=\mathrm{P} \mathrm{s}-\mathrm{P} \max \sin \mathrm{\partial}
\end{aligned}
$$

Where:

$\mathrm{W} \mathrm{s}=$ angular velocity of the reference axis rotating synchronously $\mathrm{d}=$ angular displacement in electrical degree

\section{Conclusion}

The research performed in the program of the ETAP was useful in the DFIG wind turbine power demonstration. Originally, the results of the load flow clearly show that the DFIG can generate great output power at high wind speeds. In addition, by giving reactive Arrays to the grid, DFIG machines provide voltage stability. In the presented model assessment, two hypotheses are established. First, the micro-grid research system is expected to be equal, which means no single-phase demands or imbalanced three-phase demands are taken into account. Second, there is no interplay between both the Generating units and the network. Another thing to consider is the action that proceeds the tripping. Pre-fault results are the same, implying that fast transients do not cause safety relays and that long-term stability is unaffected. The simulation results revealed that the similarities between the results of the outcome of these two different evaluation systems support the feasibility of the usage of a double-fed induction generator to increase the multi-transient machine's stability. The system that has been created can simply be adapted to other big wind farm models that have been tested for erroneous running.

\section{References}

[1] C. S. Desmoulins, P. Demopoulos. "Electrical Transients of Wind turbines In A Small Power Grid". IEEE Transactions on Energy Conversion. September 1996; Volume 11: No 3.

[2] Vishal Vaman Mehtre, Shripad Ganapati Desai, Prof. Dr. D.S. Banker. "Analysis of a Doubly Fed Induction Generator based Wind Farm". IEEE International Conference on Technological Innovations in ICT For Agriculture and Rural Development. 2016: 7.

[3] Amman Jaiswal, Mukesh Kumar, Abhinav Kumar, Rahul Kumar. "Load Flow and Stability Analysis of Multi-Machine Power Systems in ETAP". Maulana Abdul Kalam Azad University of Technology (MAKAUT) 2018.

[4] Archana R1, Subramaniya Siva A2. "A Perspective Analysis for the Impact of PV and Wind Hybrid Distributed Generation". International Journal of Advanced Research in Electrical. April 2018; 7(4): 7.

[5] B A shad, A Siswanto, I C Gunadin, and Yusran. "Stability Analysis and Fault Changes on Wind Turbine Effect in Multi-Machine Power System". Materials Science and Engineering. IOP Conference Series; 2019; Indonesia: B A Shad; 2020.p. 7.

[6] Thomas Ackermann. "Wind Power in Power Systems". Edited by T. Ackermann: John Wiley \& Sons; 2005. 684-745 
[7] J. T. de Oliveira, M. F. de Medeiros Jr., and C. B. M. Oliveira. "Development of Modules for Transient Stability Studies of Power Systems with Wind Turbines in Different Simulation Platforms”. IEEE. 2006.

[8] B. Dong, S. Asgarpoor, and W. Qiao. "Voltage Analysis of Distribution Systems with DFIG Wind Turbines". IEEE. 2009.

[9] T. A. and A. M., "Modeling Issues of Grid-Integrated Wind Farms for Power System Stability Studies," Model. Control Asp. Wind Power Syst., 2013, doi: 10.5772/54612.

[10] Napalm, Prof. S.U Kulkarni. "PMSG Based Wind Farm Analysis in ETAP Software". IJSRSET $.2017 ; 3(3): 5$.

[11] Hei Yan Lai, Weijie Mai, C. Y. Chung. "Educational Simulation Platform for Micro-grid". IEEE.2014: 7

[12] Vijay Ray, Summit Sahrawi, Kamet Pander. "Transient Stability Analysis of Wind Turbine Based MicroGrid using ETAP Software". International Journal of Engineering Research \& Technology (IJERT). April- 2014; 3(4):4.

[13] Prescient Debra, AK shay Kudu, M.R. Ram ekes, D.R. Tutakane. "Analysis of DFIG based Wind Energy System with Grid Integration under normal and abnormal conditions". IOSR Journal of Electrical and Electronics Engineering (IOSR-JEEE). Mar - Apr. 2015; 10(2): PP 46-52.

[14] Vishal Vaman Mehtre, Shripad Ganapati Desai, Prof. Dr. D. S. Banker. "Power Comparability Analysis of DFIG And SCIG based Wind Farm". IJSRSET. 2016; 2 (3): 5.

[15] M .Saleh Ebn Sharif, M. Monower Zahid Khan, M . Moniruzzaman, Anamika Bose. "Design, Simulation and Stability Analysis of Wind-PV-Diesel Hybrid Power System Using ETAP”. American Journal of Modern Energy .2017; 3(6): 121-130.

[16] Heping Zou, Hui Sun, Jiyan Zou. "Fault Ride-through Performance of Wind Turbine with Doubly Fed Induction Generator”. IEEE. 2007. 